Original Research Paper

\title{
Intercropping Agricultural Practices by Improving Maize Early Growth Process: A Bio-Statistical Approach
}

\author{
${ }^{1}$ Dago Dougba Noel, ${ }^{2}$ Tuo Yalamoussa, ${ }^{2}$ Niamien Coffi Jean Magloire, \\ ${ }^{1}$ Moroh Aboya Jean-Luc, ${ }^{1}$ Dagnogo Dramane, ${ }^{1}$ Kablan Gnoan Aka Justin, \\ ${ }^{3}$ Oro Zokou Franck, ${ }^{1}$ Lallié Hermann-Désiré, ${ }^{3}$ N' Guessan Aya Carine, ${ }^{1}$ Loukou \\ N'Goran Etienne, ${ }^{1}$ Diarrassouba Nafan and ${ }^{4}$ Diomandé Dramane \\ ${ }^{1}$ Département de Biochimie-Génétique UFR Sciences Biologiques Université Peleforo Gon Coulibaly BP 1328 Korhogo \\ ${ }^{2}$ Département de Biologie Animale UFR Sciences Biologiques Université Peleforo Gon Coulibaly BP 1328 Korhogo \\ ${ }^{3}$ Département de Biologie Végétale UFR Sciences Biologiques Université Peleforo Gon Coulibaly BP 1328 Korhogo \\ ${ }^{4}$ Département des Sciences et Technologie des Aliments, Université Nangui Abrogoua 02 BP 801 Abidjan 02, Côte d'Ivoire
}

Article history

Received: 06-04-2019

Revised: 04-05-2019

Accepted: 25-05-2019

Corresponding Author: Dago Dougba Noel

Département de Biochimie-

Génétique UFR Sciences

Biologiques Université Peleforo

Gon Coulibaly BP 1328

Korhogo

Email: dgnoel7@gmail.com

\begin{abstract}
Fertile soil pressure represents a crucial concern vis-à-vis of agricultural crop yield improvement in several southern countries. Environmental concerns and soil low fertility as well as a rapid demographic development and as well intensive industrial exploitation with regard ground resource, drastically contribute in reducing agricultural land availability. We believe that multiple culture and/or intercropping experimentation designs, integration in southern countries agricultural practices, could partially overcame fertile soil pressure issues. The main types of intercropping include mixed intercropping, row intercropping and strip intercropping. Here we assessed maize/cowpea intercropping patterns as well as maize monoculture systems. For this purpose, experimental dispositive is as following; 5 parcels including sole maize plants, 5 parcels with alternation of maize and cowpea plots on the same row (strip intercropping) and 5 parcels including maize and cowpea alternation rows (row intercropping), by a computational statistical approach with the purpose to promote mixed crops practices in contrasting fertile soil availability concerns, optimizing maize plants growth process. Growth data (plant height and plant leave number) apropos 52 maize plants for each above described experimental sites were collected during 9 weeks and processed by own $\mathrm{R}$ script, including descriptive and analytical statistical surveys. Findings clearly shown a positive impact of intercropping practices in accelerating maize early growth process. Maize and cowpea rows intercropping exhibited a good performance in term of accelerating maize growth process as opposite to maize monoculture $(\mathrm{p}<0.03)$ and maize/cowpea strip intercropping parcels $(\mathrm{p}<0.001)$. This study highlighted the usefulness mixed cultures intercropping system based on maize/cowpea rows alternation planting pattern in improving maize early development and as well promoted experimental design as a valuable solution in agronomical research for contrasting agricultural concerns vis-àvis of limited productive and as well low fertile ground resources.
\end{abstract}

Keywords: Maize and Cowpea Intercropping Patterns, Maize Monoculture

\section{Introduction}

The seeming increased competitiveness of intercropping systems makes them potentially useful for adoption into low input farming systems in which options for chemical weed control are reduced or non-existent (Szumigalski and
Van, 2005). When two crops are planted together, intra and as well inter specific competition or facilitation between plants may occur (Zhang and Li, 2003). Then, Intercropping is the growing of two or more crop species simultaneously in the same field during a growing season. The intercropping of legumes with cereals offers
Science

Publications 
scope for developing energy-efficient and sustainable agriculture (Michael et al., 2017). Previous research studies showed that mixtures of cereals and legumes produce higher grain yields than either crop grown alone (Olufemi et al., 2001; Dapaah et al., 2003). The yield increase is not only due to improved nitrogen nutrition of the cereal component, but also to other unknown causes (Connolly et al., 2001). Several research studies highlight biological nitrogen fixation by grain legume crops (Izaurralde et al., 1992; Giller and Cadisch 1995; Peoples et al., 2002) and suggested the latter's as a significant nitrogen (N) source in agricultural ecosystems (Dakora et al., 2000). However, investigations regarding nitrogen $(\mathrm{N})$ fixation in complex cereal/legume crops mixtures are few (Stern, 1993; Peoples et al., 2002). Furthermore, cereal/legume intercropping crop scheme and/or design patterns usually includes a legume which fixes $\mathrm{N}_{2}$ that benefits the system and a cereal constituent that depends greatly on nitrogen, optimizing crop yield (Cochran and Schlentner 1995). Several experimental surveys have shown a significant direct transfer of fixed nitrogen (fixed-N) to the associated non legume species (Elgersma et al., 2000; Chu et al., 2004). Also, as previously suggested, several environmental concerns and soil low fertility as well as a rapid demographic development and intensive industrial exploitation with regard soil resource, drastically contribute in reducing agricultural land availability. Then, it appear evident that the purpose of mixing legume and cereals in the intercropping systems is to optimize the use of spatial, temporal and physical resources both above-and below ground, by maximizing positive interactions and minimizing negative ones such as competition among the components (Patrick, 2006). Several studies suggested that research should focused on manipulating the legume/cereal mixtures and establish different subsistence mechanisms that are used by the plants in stressed environments (i.e. northern area in Cote d'Ivoire). Also, hard work should be geared towards closing the current gap in rhizosphere research (Shaharoona et al., 2006; Umesha et al., 2014; Diarrassouba et al., 2015; Noel et al., 2016; Dago et al., 2018) in mixed cultures by correctly outlining the unknown factors that affects plant growth in mixtures (Connolly et al., 2001). This can lead to increased production through improved plant nutrition, as well as genetic manipulation of different plant species and management practices in the cropping systems (Patrick, 2006). Moreover, numerous studies mainly exhibited legume/cereal intercropping mixtures in agricultural practices as an eco-friendly approach for reducing weed problems via non chemical methods by improving crops yield. Indeed, several studies exhibited intercropping maize and cowpea in different patterns and mixproportions as affecting grain yield due to competition between the pair crops compared to individual cropping (Yilmaz et al., 2007; Dahmardeh et al., 2009; Takim, 2012). Also, our recent studies suggested statistical models as adequate systems in assessing experimental agriculture performance (Dago et al., 2015; 2016; 2018). Usually, experimental design in agronomic studies generate heterogenic as well as big data size allowing computational statistical tool integration in that data analysis procedure (Dago et al., 2016; Noel et al., 2019). Forecasting of crop yields is a formidable challenge (Dago et al., 2018). The main factor affecting crops yield are soil characteristic, crop-inputs supplies and weather experience by the soil crop during growth period. Quantitative data on these factors forms one approach for forecasting crop yields. The other approach uses plant vigor measured either through plant characters or through remotely data. Also, soil properties are greatly influenced by climatic conditions. These effects are manifested through crop stand, number of tiller, number of leaf, root and plantlet length, leaf area etc. which ultimately determine crop yield. Then several studies discussed statistical methodologies such as linear regression model and principal component regression (Jain et al., 1984; Chandrahas et al., 1989) and as well probability model based on Markov Chain (Jain and Agrawal, 1992) for crop forecasting using plant metrics parameters. Here we performed a multivariate biostatistical analysis with the purpose to highlight and promote maize and cowpea cereal intercropping experimental schemes and/or experimental designs paying attention to maize cereal early growth performance, in a low fertile soil and/or agro-climate as well as high pressure agricultural area, northern of Cote d'Ivoire (Diarrassouba et al., 2015). The present survey partially based on our recently developed computational statistical pipeline (Noel et al., 2019) implemented in R programing environment (Core Team, 2018).

\section{Materials and Methods}

\section{Experimental Design}

The experiments were conducted over a period of 9 weeks from June, 2017 to September, 2017, corresponding to the long rainy season at botanical garden in Péléforo Gon Coulibaly University (UPGC), in Korhogo (Latitude: $9^{\circ} 26$ 'North, Longitude: $5^{\circ} 38^{\prime}$ West) in northern of Cote d'Ivoire. The climate in this area is characterized by two types' Sudanese seasons; (i) dry season, from November to April, punctuated by Harmattan (dry wind from the Sahel) and (ii) rainy season from June to November. The climate of the area is the maritime sub-equatorial with average temperatures that range of $24^{\circ} \mathrm{C}-33^{\circ} \mathrm{C}$ and total annual rainfall that range of $1100-1600 \mathrm{~mm}$ (Diarrassouba et al., 2015). The experiment was randomized complete block design with 5 replications in three different experimental schemes and/or designs as following; (i) parcels including maize monoculture referred as intercropping system 1 (IS1), (ii) parcels with alternation of maize and cowpea 
plots on the same row (strip intercropping), named intercropping system 2 (IS2) and (iii) parcels with alternation of maize and cowpea row (row intercropping), referred as intercropping system 3 (IS3) (Fig. 1). Each elementary parcel is made up of 5 lines, each with 12 pockets with gaps of $0.80 \mathrm{~m}$ between the lines and $0.5 \mathrm{~m}$ between the pockets on the same line (Fig. 1). Taking together our experiment included 15 elementary plot for the entire device. Then, experimental site area has been estimated around $400 \mathrm{~m}^{2}(20 \mathrm{~m} \times 20 \mathrm{~m})$. Next, plowing and leveling and picking were done few days before sowing. It is noteworthy to underline that maize and cowpea seeds were previously treated with fungicides before sowing. Sowing was carried out in pockets (4 grains per pocket). Once plants emerged, plants pair off for each considered pocket was performed about 15 days later. Weeding was done regularly throughout the cycle and NPK intake was done during vegetative phase. So, each maize and/or maize/cowpea pair plot received $25 \mathrm{~kg} . \mathrm{h}^{-1}$ of NPK and as well urea at sowing.

\section{Maize Growth Features Data Collection and Data} Pre-Treatment And/Or Pre-Processing

The present survey aims to assess maize early growth features performance in two (2) cereal/legume intercropping pattern schemes referred as strip intercropping and row intercropping and as well in maize monoculture experimental designs. The experiment was conducted in a randomized complete block design with each block of treatments replicated five (5) times. We collected, maize plants height and leaves number data with regard 52 plants for each processed intercropping pattern systems as well as maize monoculture plot (Fig. 1). Indeed, 52 maize plants via a simple random sampling method were selected in the previous described 15 elementary plots (Fig. 1). Growth parameters were evaluated using a centimeter as scale of measurement $(\mathrm{cm})$. Maize plants height have been measured from the ground level to the end of the longest petiole.
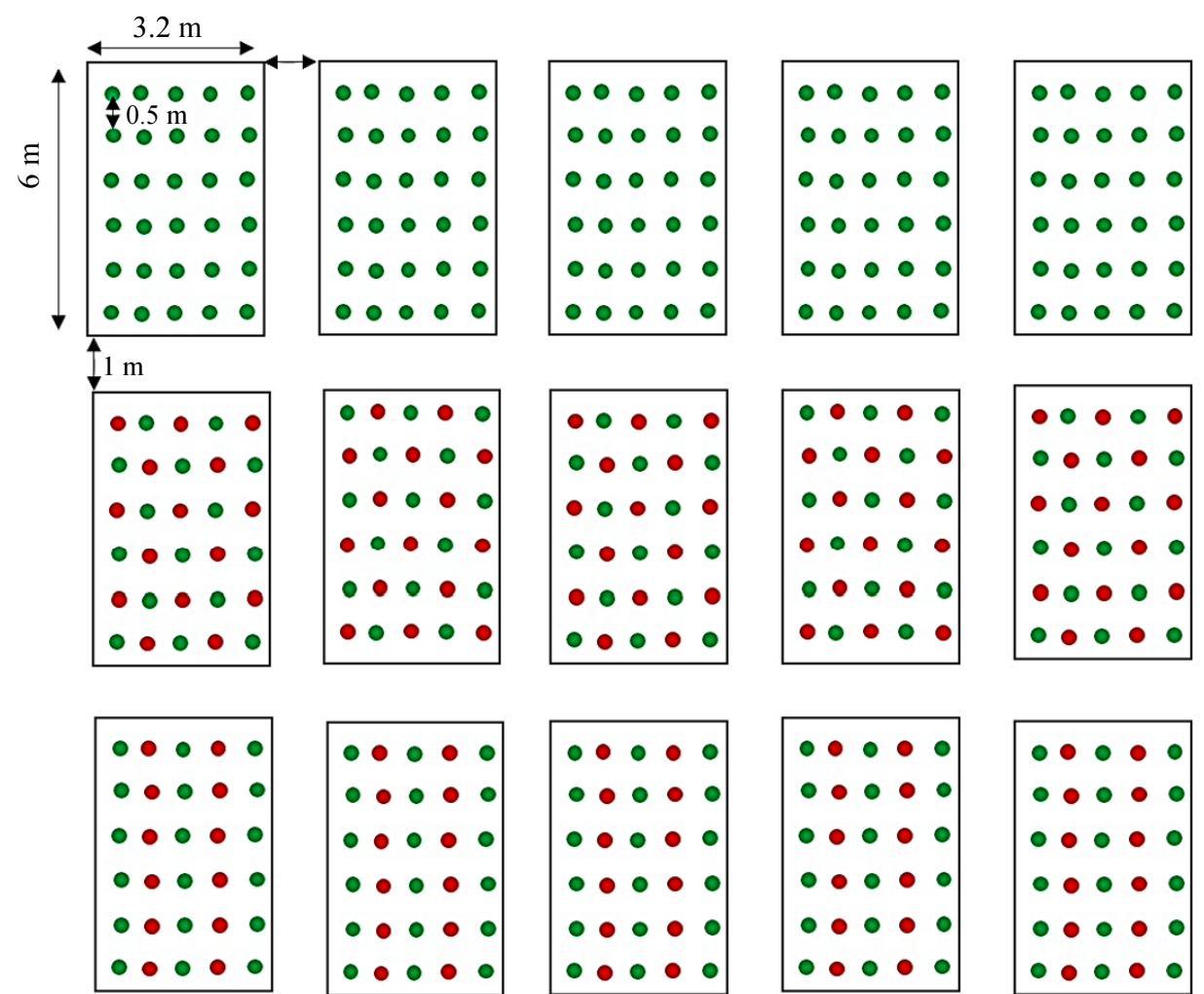

Intercropping

System 1
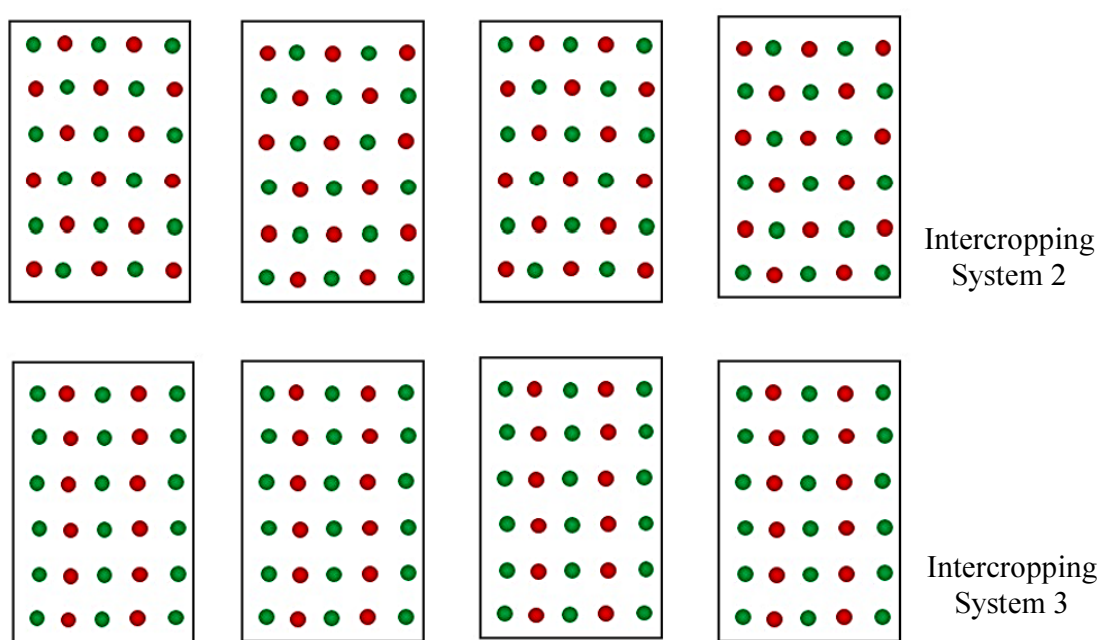

Intercropping System 3

- Maize plants • Cowpea plants

Fig. 1: Illustration of experimental design including the 15 elementary experiences: five (5) parcels including maize monoculture (Intercropping System 1: IS1), five (5) parcels with alternation of maize and cowpea plots on the same row (Intercropping System 2: IS2) and five (5) parcels with alternation of maize and cowpea row (row intercropping; Intercropping System 3: IS3) 
Also, maize leaves number per plant was counted weekly. Maize growth features data have been collected through nine (9) weeks and summarized as following: (i) plants height and leaves number collected data during week 1, 2 and 3; (ii) plants height and leaves number recorded during week 4,5 and 6 and plants height and leaves number data collected from week 7, 8 and 9. We performed maize growth features data normalization (maximum normalization) before statistical analysis aiming to reduce that data variability bias. It is noteworthy to underline that in statistics, normalization refers to the creation of shifted and scaled versions of statistics, where the intention is that these normalized values allow the comparison of corresponding normalized values for different datasets (heterogenic data) in a way that eliminates the effects of certain gross influences, as in an anomaly time series (Dodge 2003; Dago et al., 2015).

\section{Computational Statistical Analysis}

The statistical analysis was carried out using $\mathrm{R}$ software (version 3.5.1). For this purpose several $\mathrm{R}$ package and/or libraries such as "gplots", "corrplot", "qgraph", "sem", "psych", "vioplot", "nFactors" and "ape" and "ggplot2" have been installed and loaded in R programing environment and/or console by applying library() function. Descriptive statistic englobed Pearson correlation and as well Euclidean distance of Pearson correlation heat-map and phylogenetic clustering graphics via heatmap.2 () and plot (as.phylo ()) script and/or function respectively. This analysis also included maize growth features variance clustering analysis by running above mentioned heatmap. $2 \mathrm{R}$ function. Also, we performed a multivariate statistical survey based on $\mathrm{R}$ fitting curve analysis. Indeed, $\mathrm{R}$ software curve fitting function (Sandra, 1994; William, 1984) which is the process of constructing a curve, or mathematical function, that has the best fit to a series of data points (Halli and Rao, 1992), possibly subject to constraints. Interestingly, fitted curves can be used as an aid for data visualization (Halimah et al., 2009; John, 2009) to summarize the relationships among two or more variables (Sandra, 1994). So, all analyzed statistical parameters curve in the present survey have been fitted by maize growth parameters (plant height and plants leaves number) in processed Intercropping System 1 (IS1). Maize growth features data distribution function were realized by $\mathrm{R}$ plot $(e c d f())$ function for each considered intercropping experimental site by assessing maize weekly growth development dynamism, while both multivariate boxplot and as well Principal Component Analysis (PCA) graphics, were generated with the purpose to visualize maize growth data features variability (variance). The biplot provides a useful tool for data analysis and allows for the visual appraisal of the structure of large data matrices. It is especially effective in principal component analysis, where the biplot can show inter-unit distances and indicate clustering of units as well as display variances and correlations of the variables (Gabriel and Odoroff, 1990). Here we used biplot for the clustering of week 1-3, week 4-6 and week 7-9 factors basing on maize growth features variance. Analysis of variance (ANOVA) for linear model fit, compute an analysis of variance table for the three processed intercropping systems (IS1, IS2 and IS3) linear model fits via the following script: anova (object, ..., scale $=0$, test $=" F^{\prime \prime}$ ). Results table will contain $\mathrm{F}$ statistics and $\mathrm{P}$ values comparing the mean square for the row to the residual mean square. The comparison between our three intercropping schemes models will only be valid if they are fitted to the same dataset (Chambers, 1992). A crucial decision in exploratory factor analysis is how many factors to extract. Parallel analysis in principal component analysis is a useful method to established the number of principal component needed in a multi-variant statistical analysis (Franklin et al., 1995) in which theoretical estimate variance is computed and compared to observed (real variance) or experimental data. The output file of this analysis is a scree graph. So, the "nFactors" package offers a suite of functions to aid in this decision (Zwick and Velicer, 1986). Next, we evaluated relationship between maize plant height and leaves number parameters for each considered week intervals (week 1-3, week 4-6 and week 7-9) in the three (3) processed maize/cowpea intercropping experimental sites by parallel PCA survey in detecting needed components. Inferential and/or analytical statistical analysis with regard presently performed biostatistical survey consisted in one sample statistical test and as well Fisher test in comparing maize growth features data variance differences.

\section{Results}

Pearson Correlation and Variance Analysis Weighing Maize and Cowpea Intercropping Culture Systems Concordance and Dynamism

Pearson correlation survey exhibited parcel and/or culture system preeminence regardless processed maize plants growth features (leaves number and plants high) as well as data collection periods (Fig. 2A). Also, findings revealed a high intra-correlation coefficient between maize growth features in intercropping systems 2 and 3 (IS2 and IS3) in comparison to experimental scheme including maize monoculture (Fig. 2). Further, the same survey suggested a relative good agreement $\left(\mathrm{R}^{2}=0.32, \mathrm{p}<<0.05\right)$ between intercropping schemes 2 and 3 (IS2 and IS3) in assessing maize plants growth process as opposite to intercropping system $1 \quad\left(\mathrm{R}^{2}=0.19-0.23, \quad \mathrm{p}<0.05\right) \quad$ (Fig. 2A). 

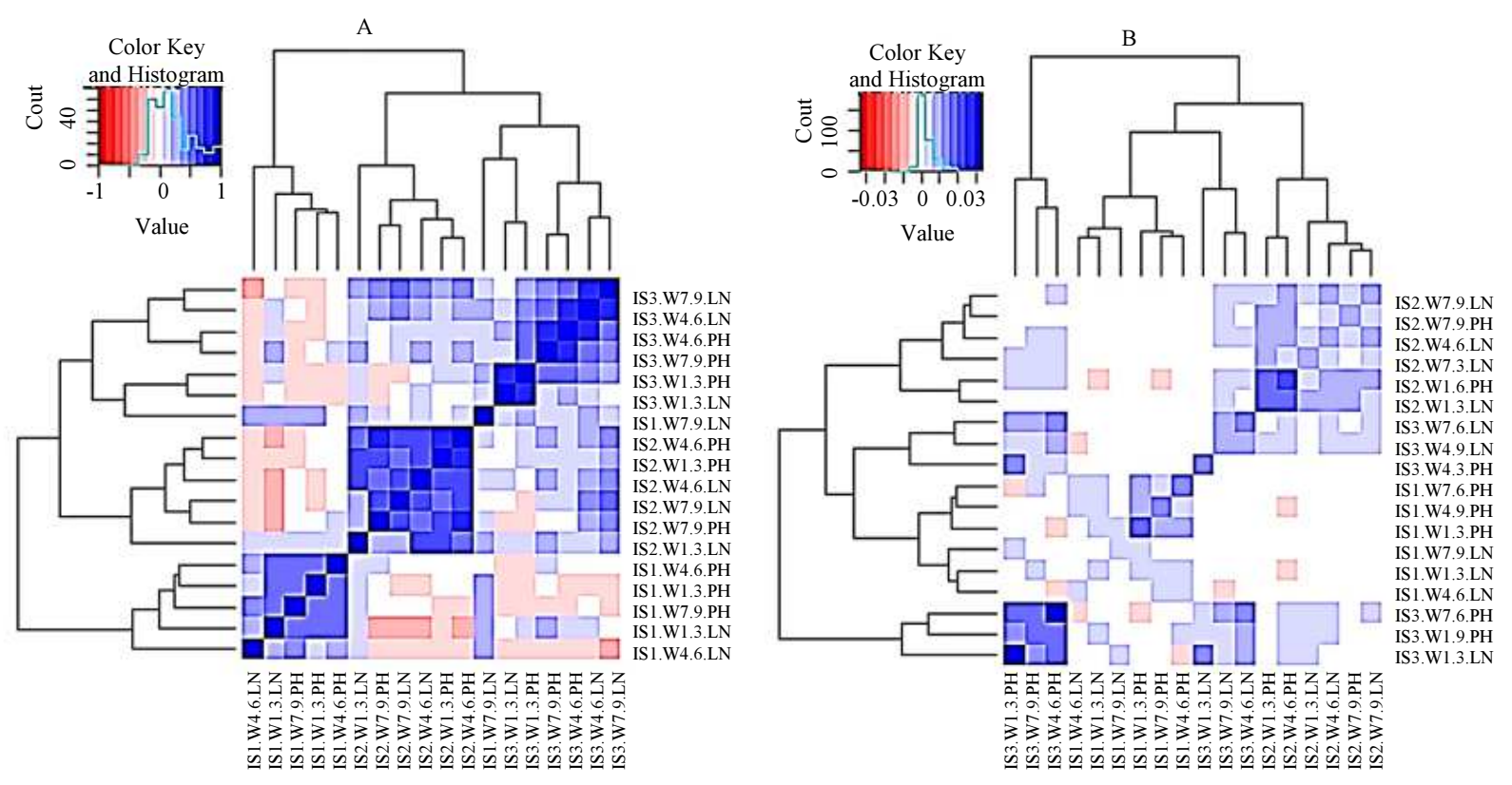

Fig. 2: (A) Pearson correlation and (B) variance relationship heatmap graphs in evaluating maize monoculture parcels (Intercropping System 1: IS1) and parcels with alternation of maize and cowpea plots on the same row (Intercropping System 2:IS2) and mixed cropping scheme with alternation of maize and cowpea rows (Intercropping System 3: IS3) concordance by evaluating maize plants growth features (leaves number and plants height) performances. i.e.: IS3.W1.3.LN acronym refers to maize Leave Number features collected in maize/cowpea Intercropping Scheme 3, during week 1-3 interval, while IS3.W1.3.PH acronym indicates maize Plants Height features collected in maize/cowpea Intercropping Scheme 3 during week 1-3 interval period.

Table 1: One sample statistical test assessing IS2 and IS3 maize and cowpea intercropping systems by assuming maize experimental parcel (IS1) as benchmark and/or reference $(\mathrm{df}=311)$.

\begin{tabular}{lll}
\hline & $\begin{array}{l}\text { Maize intercropping system 2 (IS2) vs. } \\
\text { Maize culture system (IS1) }\end{array}$ & $\begin{array}{l}\text { Maize intercropping system 3 (IS3) vs. } \\
\text { Maize culture system (IS1) }\end{array}$ \\
\hline $\mathrm{p}$ & $0.05^{* *}$ & $0.00^{* * *}$ \\
$\begin{array}{l}\text { Mean value of maize features } \\
\text { (leave number and plant height) }\end{array}$ & 0.78 & 0.73 \\
$\begin{array}{l}\text { Confidence interval (95\%) } \\
\text { Statistical test power coefficient }(\mathrm{t})\end{array}$ & $0.76-079$ & $0.71-0.75$ \\
${ }^{* * *} \mathrm{p} \leq 0.05$ & -2 & -6.75 \\
\hline
\end{tabular}

${ }^{* * *} \mathrm{p} \leq 0.05$

Interestingly, parcels with alternation of maize and cowpea rows (IS3) appear more heterogenic site in term of Pearson correlation values, when compared to the intercropping schemes 1 and 2 (Fig. 2A). Remarkably, variance graphic survey confirmed parcels with alternation of maize and cowpea rows (IS3) dynamism especially for processed maize plants height features as opposed to parcels with alternation of maize and cowpea plots on the same row (IS2) (Fig. 2B). Descriptive and analytical statistic test (one sample statistical test) assuming maize parcel (IS1) as benchmark, confirmed previous observed intercropping systems performance differences by assessing maize plants growth parameters and suspected a high growth performance of maize in parcels with alternation of maize and cowpea rows (Table 1).
Multivariate, $R$ fitting and Principal Component Statistical Survey Estimating Maize and Cowpea Culture Intercropping Systems Dynamism

In this chapter we performed several descriptive and analytical statistical analysis with the purpose to evaluate maize and cowpea experimental parcel intercropping schemes performances. Statistical distribution function curves referred to processed experimental intercropping sites proposed intercropping system 3 (IS3) as exhibiting the highest dynamism in term of maize plants development (growth) as opposed to intercropping system 1 and 2 (Fig. 3A, B and C). Boxplot multivariate statistical survey (Fig. 3D) showed higher data variance and/or variability evaluating maize plants growth features in experimental parcel with alternation of maize and cowpea rows (IS3) in comparison to both intercropping schemes 1 and 2 (IS1 and IS2). 


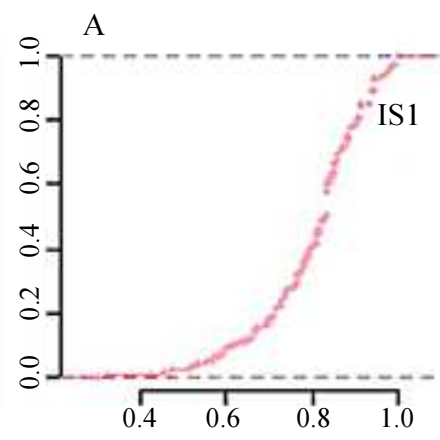

D

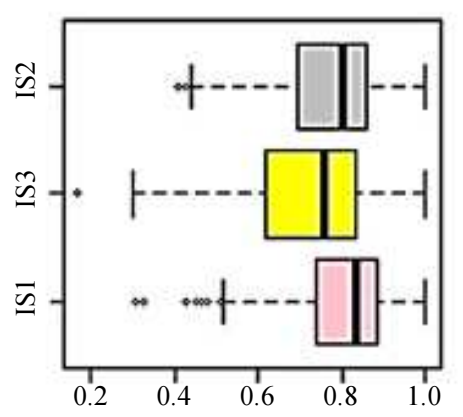

G

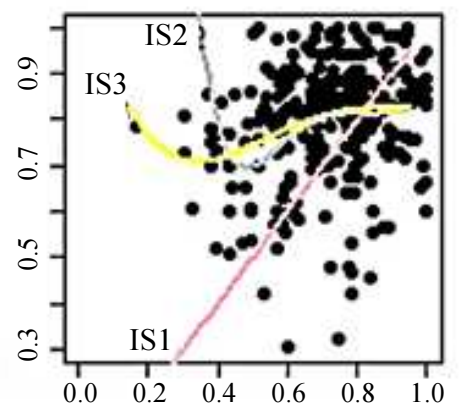

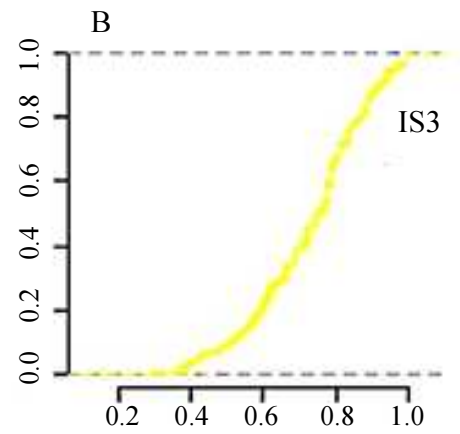

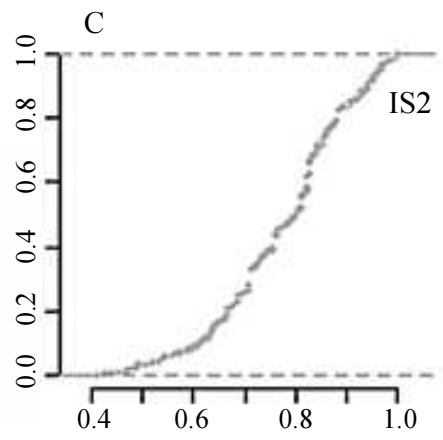

E
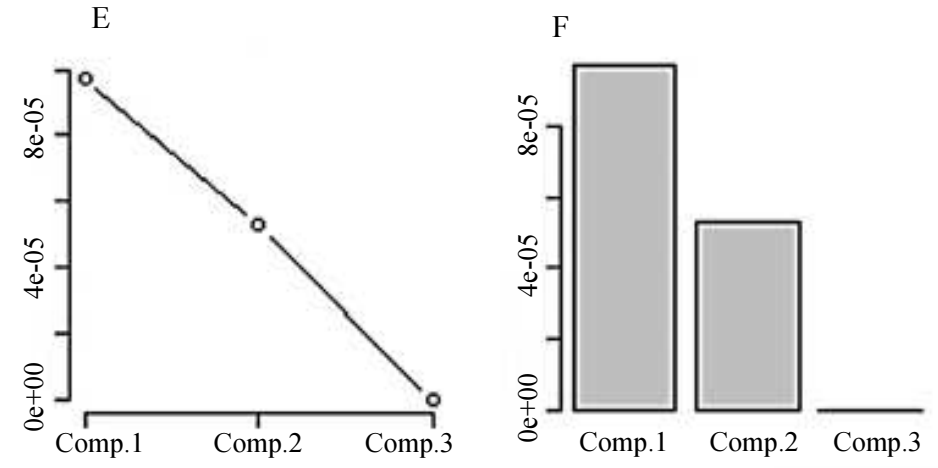

$\mathrm{H}$

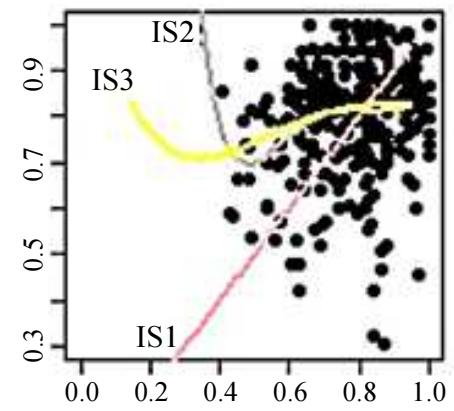

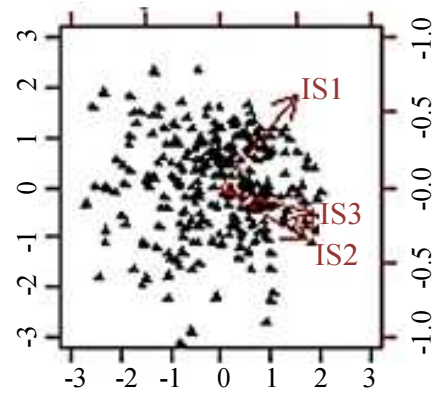

Fig. 3: (A), (B) and (C) distribution functions of maize leave number and height features data by processing IS1, IS2 and IS3 maize/cowpea intercropping schemes. (D): boxplot multivariate survey assessed maize/cowpea intercropping parcels maize growth data features distribution. (E) and (F): IS1, IS2 and IS3 intra-parcel variance estimation. $(\mathrm{G})$ and $(\mathrm{H})$ : $\mathrm{R}$ fitting curve survey in evaluating IS1, IS2 and IS3 maize/cowpea intercropping planting design pattern mathematical relationship. (I) Biplot PCA graphic highlighted maize plants population data dispersion by processing two components in assessing maize/cowpea intercropping planting systems dynamism.

Table 2: Fisher test comparing variance differences between IS1 and both IS2 and IS3 maize and cowpea intercropping experimental parcel $(\mathrm{df}=311)$.

\begin{tabular}{lll}
\hline & $\begin{array}{l}\text { Maize/cowpea intercropping system 2 (IS2) vs. } \\
\text { Cropping including maize culture only (IS1) }\end{array}$ & $\begin{array}{l}\text { Maize/cowpea intercropping system 3 (IS3) vs. } \\
\text { Cropping including maize culture only (IS1) }\end{array}$ \\
\hline $\mathrm{p}$ & $0.85^{\mathrm{NS}}$ & $0.00^{* * *}$ \\
Variance ratio difference & 0.98 & 0.62 \\
Confidence interval (95\%) & $0.78-1.22$ & $0.5-0.77$ \\
Statistical test power (F) & 0.98 & 0.62 \\
\hline
\end{tabular}


In addition, variance differences (component 1> component 2> component 3 ) between analyzed maize/cowpea intercropping systems have been supported by presently performed principal component analysis (Fig. 3E and F). Next, we focused our attention in evaluating the mathematical relationship between IS1, IS2 and IS3 maize/cowpea intercropping agricultural schemes by an $\mathrm{R}$ fitting curve survey. Interestingly, results with regard that survey displayed high growth performance of maize plants in IS3 intercropping system as opposed to maize in IS2 experimental scheme when IS1 intercropping system was assumed as reference (Fig. 3G and $\mathrm{H}$ ). Variance analysis suspected high variability (high dynamism in maize plants growth process) with regard both IS3 and IS2 maize and cowpea intercropping agricultural systems as opposite to experimental site including sole maize crop (Fig. 3E and F). Remarkably, dispersive attitudes with regard IS3 and IS2 maize/cowpea intercropping agricultural systems were confirmed by biplot principal component survey (Fig. 3I). These results suggested a relative concordance between parcels with alternation of maize and cowpea plots on the same row (IS2) and parcels with alternation of maize and cowpea rows (IS3) in improving maize culture development and/or growth dynamism. Fisher statistical test in comparing analyzed maize and cowpea intercropping systems, highlighted a significant variance ratio difference $(p<0.05)$ between parcels with alternation of maize and cowpea rows (IS3) and maize cropping scheme (IS1). Further, the same survey exhibited no significant difference between IS2 and IS1 maize and cowpea intercropping systems (Table 2). Considering as a whole, the present multivariate statistical survey suspected a rapid growth of maize plants in parcels alternating maize and cowpea rows (row intercropping).

ANOVA Survey in Comparing Intercropping Schemes Performance by Processing Maize Leave Number and Plant Height Growth Features

Here, we analyzed separately processed maize growth parameters (maize plant height and maize plant leaves number). Analysis of variance concerning both processed maize growth features in the different intercropping experimental sites (IS1, IS2 and IS3) showed a good performance (Fig. 4) of parcels with alternation of maize and cowpea rows (IS3) when compared to parcels with alternation of maize and cowpea plots on the same row (IS2) $(\mathrm{p}<0.001)$ and to experimental site including sole maize crops (IS1) $(\mathrm{p}<0.0001)$. Also, the present analysis by comparing maize plants growth features in IS1, IS2 and IS3 intercropping experimental sites suggested high confidence interval and/or high variance variability for maize plants height growth parameter (Table 3). However, it is noteworthy to underline that global ANOVA test performed on maize plants height and as well leaves number growth features, suggested a strong significant difference $(p<<0.05)$ with regard variance parameter, by processing IS1, IS2 and IS3 maize/cowpea intercropping experimental sites (Table 3). Taking together, this survey suggests the propensity of parcels with alternation of maize/cowpea rows (IS3) in accelerating maize plants growth process.

\section{Performance Assessment of Pearson Correlation Coefficient between Maize Growth Features in Maize/Cowpea IS3 Intercropping Scheme}

Here we focused on maize plant development in parcels with alternation of maize and cowpea plants rows (IS3 intercropping system), since previous results exhibited that intercropping scheme as improving and as well accelerating maize early growth process (Fig. 3 and 4). The present Pearson correlation analysis (Fig. 5) accorded preeminence to collected growth features data recorded during week 1-3 interval (Fig. 5B) by exhibiting the highest correlation between maize plants height and leaves number parameters $\left(\mathrm{R}^{2}=0.8\right)$ as opposed to maize growing features data collected during week 4-6 and week 7-9 intervals. Also, the same analysis displayed a significant high correlation $\left(\mathrm{R}^{2}>0.75, \mathrm{p}<0.05\right)$ between processed maize plants height and leave number features for the first seven (7) weeks (Fig. 5A).

Table 3: ANOVA table by comparing IS1, IS2 and IS3 maize/cowpea intercropping experimental schemes in supporting maize plants development.

\begin{tabular}{|c|c|c|c|c|c|c|}
\hline \multicolumn{4}{|c|}{ Maize plant height } & \multicolumn{3}{|l|}{ Maize leave number } \\
\hline No difference & Estimated Difference & SD & $\mathrm{p}$ & Estimated Difference & SD & $\mathrm{p}$ \\
\hline IS2-IS1 $==0$ & -2.05 & 0.62 & $0.003^{* *}$ & -0.12 & 0.07 & $0.18^{\mathrm{NS}}$ \\
\hline IS3-IS1 $==0$ & 2.01 & 0.61 & $0.003^{* *}$ & 0.23 & 0.06 & $0.002^{* *}$ \\
\hline IS3-IS2 $=0$ & 4.06 & 0.7 & $<0.001^{* * *}$ & 0.35 & 0.08 & $<0.0001^{* * *}$ \\
\hline
\end{tabular}

$\mathrm{p}=0.00$ for ANOVA global test by analyzing maize plant height and leave number growth features in the three processed maize and cowpea intercropping systems. SD: standard deviation. ${ }^{* * *} \mathrm{p}<0.005$ and ${ }^{\mathrm{NS}} \mathrm{p}>0.05$ 

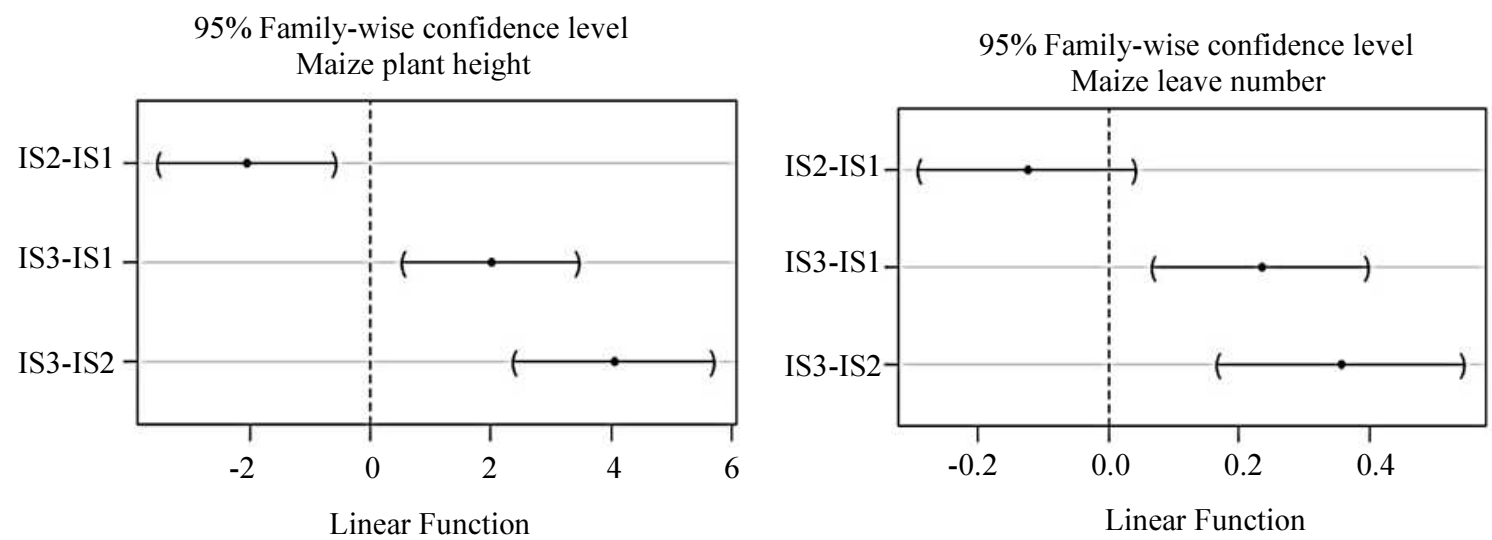

Fig. 4: ANOVA linear function measuring maize plant height and leaves number features variance difference, by processing IS1, IS2 and IS3 maize/cowpea intercropping design planting patterns experimental sites.

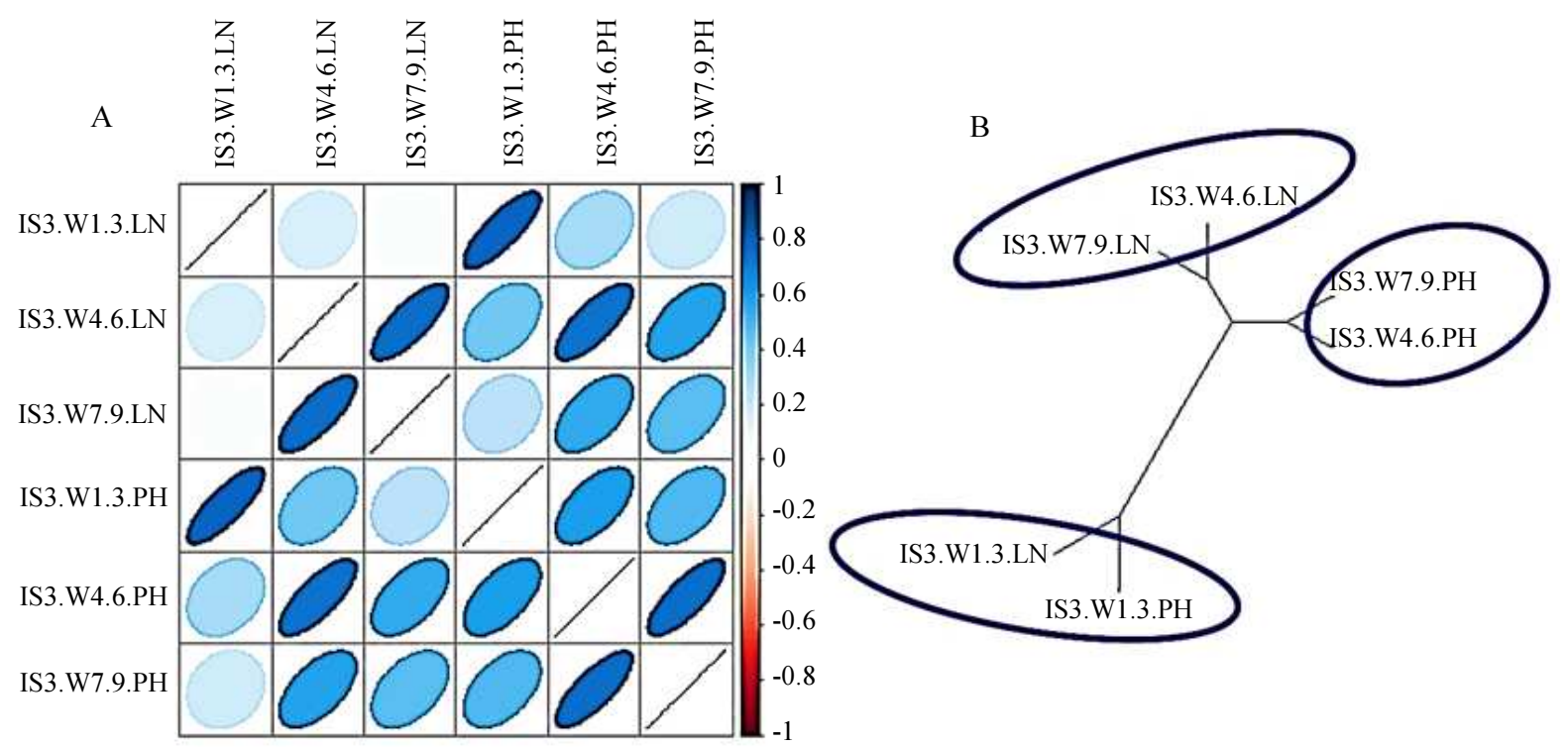

Fig. 5: Pearson correlation analysis measuring maize growth parameters concordance in maize/cowpea intercropping plating design pattern based on maize and cowpea rows alternation scheme (Intercropping System 3: IS3) assessing maize plants growth process.

Interestingly, phylogenetic tree referred to Euclidian distance of Pearson correlation confirmed non-significant difference between plant growth features after the seventh week (Fig. 5B). So, findings suspected maize plant growth process during the first three week as a period normalizing the relationship between plants height and plants leave number features (Fig 5A and B). Indeed, correlation among plant height and plant leave number resulted to be higher $\left(\mathrm{R}^{2}=0.8\right)$ for week 1-3 interval in comparison to the other considered week intervals $\left(\mathrm{R}^{2}=0.75\right.$ for week 4 6 and $R^{2}=0.46$ for week 7-9) (Fig. 5B). These results suggested a slowdown in maize leaf germination after the third week. Interestingly, maize plants leaf germination slowdown is accentuated $\left(\mathrm{R}^{2}=0.8>\mathrm{R}^{2}=0.75>\mathrm{R}^{2}=0.46\right)$ with the growth of the plants (Fig. 5B). In the other word, our survey supported inverse relationship between maize plant growth and leaf germination.

Parallel Principal Component Analysis (PCA) Discriminating Component Number in Explaining Maize Data Variability in IS3 Intercropping Site

A crucial decision in exploratory factor analysis is how many factors to extract. Parallel analysis in PCA survey is a useful method to established the number of principal components and/or factors needed in a multi-variant 
statistical analysis in which theoretical estimate variance is computed and compared to observed (real variance) or experimental data. The output file of our analysis is a scree graph (Fig. 6), where two components and/or factors displayed observed variance (black dots) higher than theoretical variance (yellow dots) (Fig. 6B). In the other word, presently parallel PCA survey findings discriminated 2 factors as statistically significant in explaining and/or justifying presently processed data dispersion and/or dynamism (Fig. 6). Also, parallel principal component analysis suggested these two factors (components 1 and 2) Eigen values higher than established theoretical mean value (Fig. 6A). Then, the present survey supposed two optimal coordinate as suitable (Fig. 6A) for the subjacent maize growth features data dispersion analysis.

\section{Multivariate Analysis Assessing IS3 Intercropping Experimental Site Performance by Maize Growth Features Data Dispersion}

We focused here on data dispersion for each considered maize plants growth parameters with the purpose to highlight weekly plant development processes dynamism. The present multivariate statistical survey clearly exhibited maize plants height growth features data collected during week interval 1-6 as the main source of that data variability (Fig. 7). Interestingly, this result displayed a consistent agreement with above performed parallel principal component analysis (PCA) that predicted two factors in explaining maize growth features data variability in IS3 intercropping site. So, merging the present results (Fig. 7) with those of previous parallel PCA analysis (Fig. 6), suggested maize plant height features recorded during both week 1-3 (IS3.W.1.3) and 4-6 (IS3.W.4.6) intervals as satisfactory factors explaining maize plants development dynamism in IS3 intercropping experimental site. In addition, Fisher test shown a significant difference $(p<<0.05)$ in term of variance comparison between maize height growth features dynamism referred to both week 1-3 (IS3.W.1.3) and 4-6 (IS3.W.4.6) intervals and the other's processed maize growth parameters (maize plant height and as well maize leaves number) collected during week 1-3 and 4-6 and 7-9 intervals (Table 4 ). Also, it is noteworthy to underline that the present multivariate analysis supposed the high susceptibility of maize plants height component in reacting to IS3 intercropping scheme stimulus as opposed to maize plant leave number feature (Fig. 7).

\section{Performance Assessment of the Relationship between Maize Growth Parameters in Maize/Cowpea Intercropping by Processing Detected Parallel PCA Survey Factors}

The present network relationship survey clearly displayed maize plant height parameter during both week 1-3 and 4-6 intervals as main sources of maize growth data variability (Fig. 8A). Standard deviation associated to that week intervals are 0.15 and 0.26 respectively. Proportion of variance with regard maize plant height features explained by week interval 4-6 (component 1$) ; 0.58$ is higher than those explained by week interval 1-3 (component 2); 0.37. Then, component 1 and component 2 of the present PCA network survey exhibit a cumulative proportion of variance around 0.95 . Our analysis revealed a feeble impact (proportion of variance $=0.04$ ) of maize plant height feature during week interval 7-9 (component 3) in explaining maize development dynamism (Fig. 8A) in the present analyzed maize/cowpea intercropping scheme (IS3).
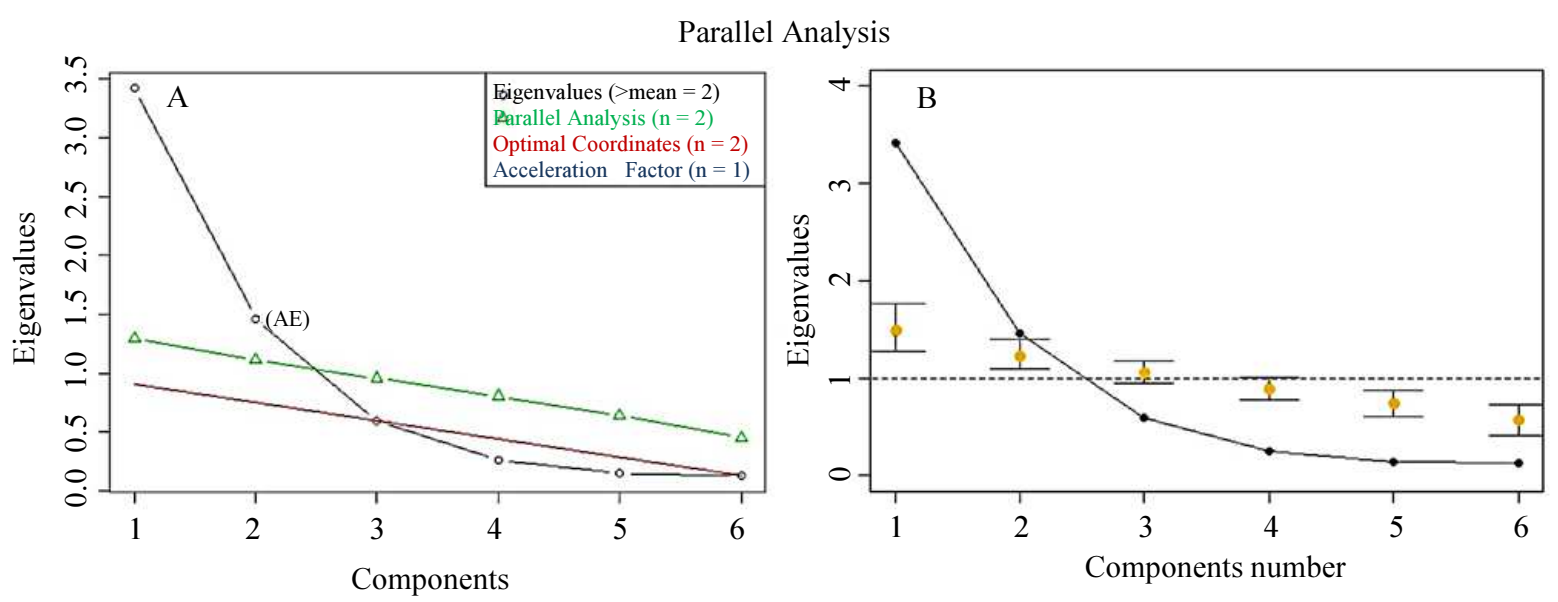

Fig. 6: Parallel Principal Component Analysis (PCA) evaluating component number (s) and/or optimal coordinate (s) suitable for maize growth feature data dispersion survey 


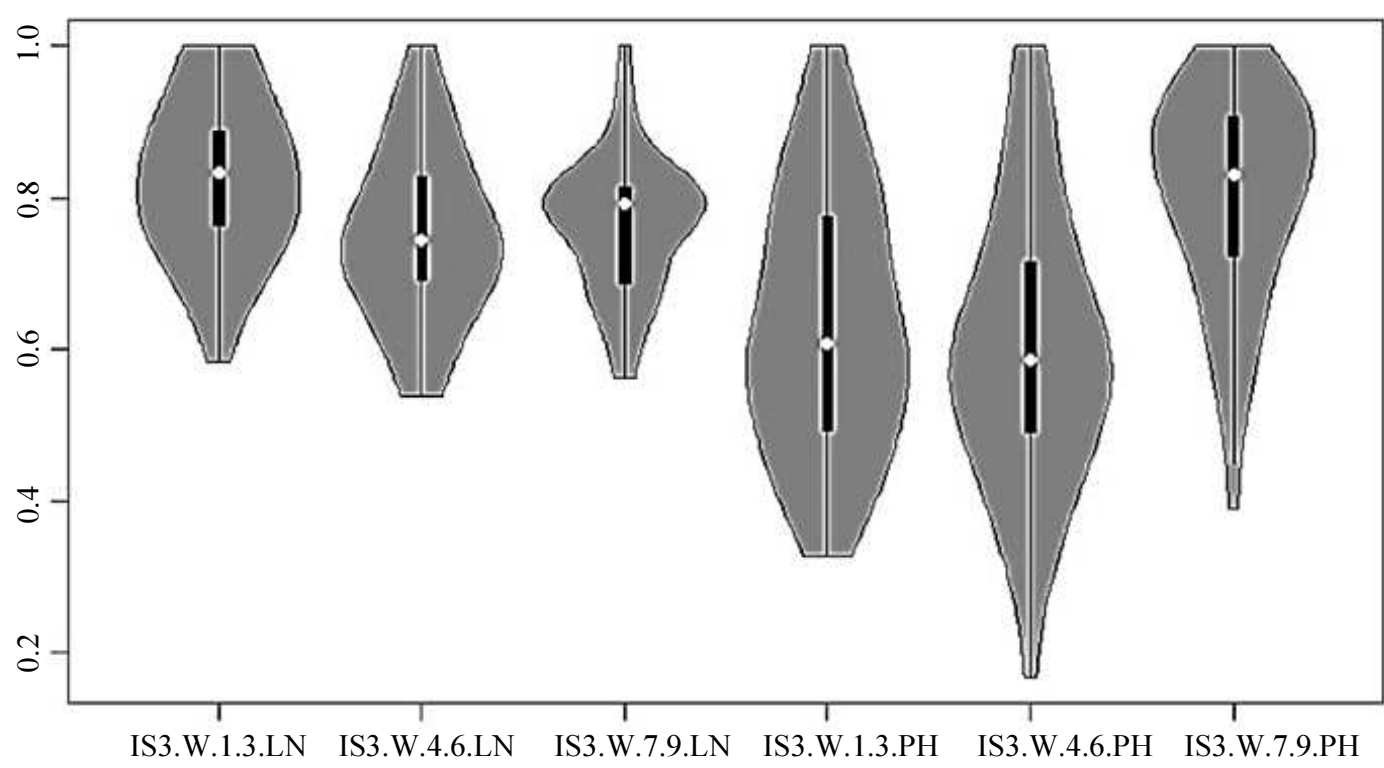

Fig. 7: Evaluation of maize plants height and leaves number growth features data dynamism (variability) in maize/cowpea intercropping plating patterns based on maize and cowpea rows alternation planting design (Intercropping System 3: IS3). i.e.: IS3.W1.3.LN acronym indicates maize Leave Number features collected in maize/cowpea Intercropping Scheme 3, during week 1-3 interval, while IS3.W1.3.PH acronym indicates maize Plants Height features collected in maize/cowpea Intercropping Scheme 3, during week 1-3 interval period.
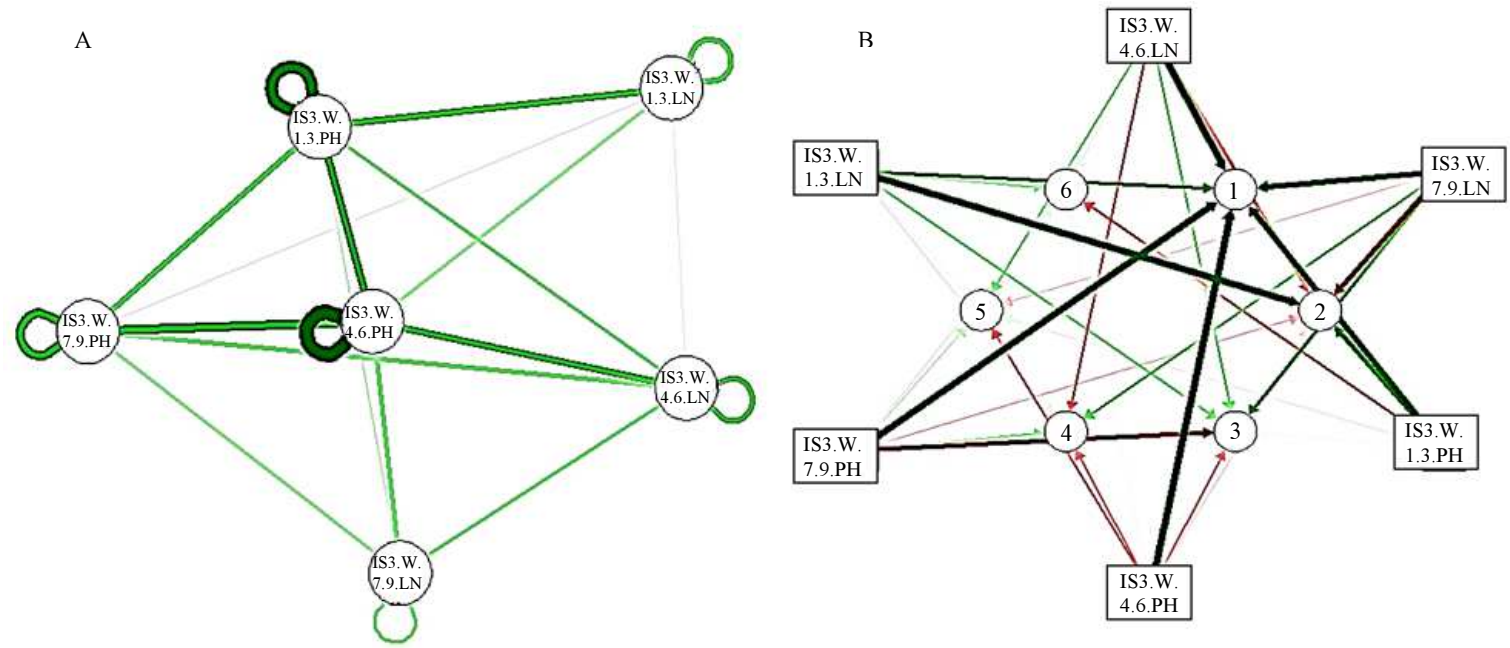

Fig. 8: Multivariate network survey by processing parallel principal component analysis (PCA) needed factors for evaluating maize plants height and leaves number growth features interactions in maize/cowpea row intercropping schemes.

Table 4: Fisher test (Degree of Freedom $=51$ ) to compare two variances assessing cereal growth process from intercropping scheme based on maize/cowpea alternation rows (IS3 intercropping system)

\begin{tabular}{|c|c|c|c|c|c|c|c|c|}
\hline & \multicolumn{4}{|c|}{$\begin{array}{l}\text { Maize/cowpea intercropping system: Maize Plant Height } \\
\text { features for week interval 1-3 (IS3.W.1.3.PH) }\end{array}$} & \multicolumn{4}{|c|}{$\begin{array}{l}\text { Maize/cowpea intercropping system Maize Plant Height } \\
\text { features for week interval 4-6 (IS3.W.4.6.PH) }\end{array}$} \\
\hline & IS3.W.1.3.LN & IS3.W.4.6.LN & IS3.W.7.9.LN & IS.3.W.7.9.PH & IS.3.W.1.3.LN & IS3.W.4.6.LN & IS3.W.7.9.LN & IS3.W.7.9.PH \\
\hline $\mathrm{F}$ & 2.51 & 2.27 & 3.71 & 1.52 & 2.87 & & 4.23 & 1.73 \\
\hline & $0.001^{* * *}$ & $0.004^{* *}$ & $0.000^{* * *}$ & $0.142^{\mathrm{NS}}$ & $0.000^{* * *}$ & $0.000^{* * *}$ & $0.000^{* * *}$ & $0.05^{*}$ \\
\hline $\begin{array}{l}95 \% \text { Confidence } \\
\text { Interval }\end{array}$ & $1.44-4.38$ & $1.3-3.95$ & $2.13-6.47$ & $0.87-2.64$ & $1.64-5.00$ & $1.49-4.51$ & $2.43-7.38$ & $0.99-3.01$ \\
\hline
\end{tabular}

$* * * \mathrm{p}<0.005$ and NS $\mathrm{p}>0.05$. i.e.: IS3.W.1.3.LN is for Intercropping System 3 (see material and method) with regard maize Leaves Number growth data features collected during Week 1,2 and 3 . 
So, findings suggested both component 1 and 2 as useful factors in predicting relationship network between processed maize growth features in IS3 experimental site. Indeed, component 1 exhibited a high concordance between maize plant height and maize leaves number features for week intervals 4-6 and 7-9 as opposed to week interval 1-3 (Fig. 8B). Interestingly, our PCA network survey suggested components 1 and 2 as better factors in explaining maize plant height (PH) and maize leave number (LN) parameters respectively for week interval 1-3 (Fig. 8B). This result confirmed previous observed difference (Fig 5 ) in maize plants growing process (in term of plant height and leave number dynamism) between (i) week interval 1-3 and both (ii) week intervals 4-6 and 7-9 suggested in parcels with alternation of maize and cowpea rows. Also, component 3 relatively provide an interaction relationship between maize plant height and leaves number features during week interval 7-9 characterized by a modest variability (Fig. 8B and Fig 7). Taking together, the present findings proposed previous discriminated component 1 and 2 as main factors explaining maize cereal growing process in presently considered IS3 intercropping site.

\section{Discussion}

Mixed culture or intercropping of legumes and cereals is an old practice in tropical agriculture that dates back to ancient civilization (Francis and Stern, 1987). The main objective of intercropping has been to maximize use of resources such as space, light and nutrients (Willey, 1990; Morris and Garrity 1993; Li et al., 2003), as well as to improve crop quality and quantity (Izaurralde et al., 1990; Mpairwe et al., 2002). Here we essayed several maize/cowpea mixed culture schemes patterns, aiming to improve maize plants growth processes in a low fertile arid ground in northern of Cote d'Ivoire. Then, results of our investigation based exclusively on a multivariate statistical analysis. Findings by a clustering survey based on Pearson correlation test suggested maize/cowpea intercropping design patterns preeminence regardless processed maize plants growth features (leaves number and plant high) as well as data collection periods. So, present findings suspected the preeminence of maize/cowpea intercropping scheme aptitude (intercropping design) in improving maize plants development (growth process) in arid ground in northern of Cote d'Ivoire. Michael et al. (2017) reported intercropping systems in poorly fertile fields as recording greater land equivalent ratio compared with fertile fields. This suggests that intercropping is more beneficial in less fertile fields and in more marginal environments. Also, Pearson clustering survey revealed a high synergy between maize plants growing process and leaf germination in maize/cowpea mixture culture systems as opposed to crop with sole maize. Several studies supported that intercrop practices can enhance weed suppression and crop production, compared with sole crops (Davis and Liebman, 2003; Saucke and Ackermann, 2006). In the same tendency, numerous surveys exhibited maize as dominant species in cereal/legume mixture culture indicating the competitiveness of maize as opposed to cowpea in mix planting pattern (Dhima et al., 2007; Yilmaz et al., 2007). These evidences could justify the high variability observed in both maize/cowpea intercropping schemes (IS2 and IS3) as opposed to cropping system including maize sole, in evaluating maize plants growth features. Spatial intercropping patterns have been studied in Northern Ghana (Agyare et al., 2006; Konlan et al., 2013) and Nigeria (Ajeigbe et al., 2010) mainly under controlled conditions. All these studies assessed the performance of different distinct alternate row intercropping patterns of maize and legumes. Rusinamhodzi et al. (2012) evoked greater land equivalent ratio when the intercrops were planted in the same row rather than in distinct rows in Central Mozambique. In addition, Konlan et al. (2013) showed intercrop advantages over sole crops that declined as the width of adjacent strips of each crop was increased. Next, performed multivariate statistical survey shown high performances of intercropping practices in improving maize plants growth dynamism. Indeed, distribution function with regard maize plant height and leaves number parameters suggested parcels with alternation of maize and cowpea rows (IS3 intercropping system) as enhancing and accelerating maize plant growing process as opposed to parcel including maize plants monoculture (IS1 intercropping system) as well as to parcels with alternation of maize and cowpea plots on the same row (IS2 intercropping system). This results were also confirmed by fitting curve analysis (Sandra, 1994; William, 1984) establishing a mathematical relationship between previous mentioned intercropping designs and/or systems planting patterns. Therefore, maize/cowpea intercropping in different patterns and mix-proportions as well as in culture disposition, may affect plants development as well as grain yield because of competition between crops compared to sole cropping (Yilmas et al., 2007; Takim, 2012). In addition, the analysis of variance (ANOVA) supported significant difference between the two maize/cowpea intercropping planting practices (IS2 and IS3 intercropping schemes) by assessing maize plant height and leaves number growth features $(p<0.0001 ; p<0.001$ respectively). This result indicated the competitiveness of maize in mix-proportions and planting patterns (Zhang and $\mathrm{Li}, 2003$ ). Further, ANOVA survey global test confirmed the good performance of maize/cowpea intercropping system including parcels with alternation of maize and cowpea rows as opposed to IS2 intercropping scheme including maize and cowpea plot alternation on the same rows and as well IS1 cropping system (maize 
monoculture practice), in promoting maize plants growth process $(p=0.00)$. Then, present survey promoted maize and cowpea row alternation mixture culture experimental design as a satisfactory approach for accelerating maize plants growth and as well productivity (Zhang and $\mathrm{Li}, 2003$ ). Taking together, findings advised that competitive and facilitative interactions in intercropping systems enhances crop development and as well productivity by arranging efficient nutrient use (Zang and Li, 2003; Ofuso-Amin and Limbani, 2007). Next, the present analysis highlighted processed maize growth features dynamism in maize/cowpea intercropping systems with alternation of maize and cowpea rows. Indeed, findings exhibited significant $(p<0.05)$ high correlation coefficient $\left(R^{2}=0.8\right)$ between maize plants height and leaves number features during plants early growing period (first three week). However, this correlation coefficient strongly decreased after the seventh month $\left(\mathrm{R}^{2}\right.$; from 0.8 to 0.46$)$, suggesting early development instant as a favorable period for maize cereal plants leaf germination. Interestingly, performed parallel principal component survey discriminated early growth period by evaluating maize height features, as satisfactory parameters explaining maize plants development and/or growth speediness in the intercropping systems referred to maize and cowpea rows alternation mix culture pattern (intercropping system IS3) as opposite to the other intercropping and/or monoculture arrangements. Considering as a whole, maize/cowpea mixed culture based on maize and cowpea rows alternation appeared to improve maize plants competiveness in their early development stage period. Principal component network analysis confirmed maize plants early (1-3 week interval) and middle (4-7 week interval) growing periods as satisfactory parameters explaining (more than $95 \%$ of cumulative variance) presently processed maize plants growth dynamism. Also, we believe that demand for labor saving technology could become a necessary condition for further agricultural intensification in southern countries at least in areas with better market access and higher opportunity costs of rural labor (Nin-Pratt and McBride, 2014). Thus, it is possible that the lack of labor-saving technology and/or mechanization limits the potential returns to certain types of land saving technology such as improved seeds and application of fertilizers and pesticides, unless such labor constraints can be overcome through mechanization (Nin-Pratt and McBride, 2014; Ndlovu et al., 2014). Presently processed intercropping systems (IS2 and IS3 inter-cropping schemes) can be easily integrated to above mentioned labor-saving technology with the purpose to improve agricultural land productivity and as well crops growth and yield. Although we provided detailed statistical survey for explaining maize growth dynamism in a cereal/legume intercropping systems, we believe that next investigation by processing either maize yield and growth features with the purpose to link cereal/legume intercropping design patterns with maize growth and yield performance in agricultural practices is essential.

\section{Conclusion}

Findings clearly shown high performance with regard maize/cowpea (cereal/legume) intercropping planting pattern in promoting early maize growth speediness as well as suggested the good propensity of maize/cowpea intercropping design pattern based on maize and cowpea row alternation in strongly improving maize cereal growth dynamism. Finally the present bio-statistical approach provided a pattern confirming the narrow relationship between experimental design in agronomic research and statistical data analysis and as well statistical model.

\section{Acknowledgements}

Authors thank Mr Soro Fokin, Mr Traoré soumaila, Mr Traoré Drissa and Mr Coulibaly Nahoua for maintenance of the experimental site (experimental device).

\section{Author's Contributions}

Dago D. Noel, Ph.D: Organized data collection; data pre-processing and/or pre-treatment as well as analysis; prepare the figures and wrote the manuscript.

Dr Tuo Yalamoussa: Set up the experimental device and read and approved final version of the paper.

Dr Niamien Coffi JM: Read and approved final version of the paper.

Mr Dagnogo Dramane and Mr Kablan Gnoan A.J.: Collected the data and participated to the data analysis.

All Authors read the paper and approve final version.

\section{Conflict of Interest}

The authors have not declared any conflict of interests.

\section{References}

Agyare, W.A., V.A. Clottey, H. Mercer-Quarshie And J.M. kombiok, 2006. Maize yields in the long-term rotation and intercropping systems in the Guinea savanna zone of Northern Ghana. J. Agron., 5: 232238. DOI: $10.3923 /$ ja.2006.232.238

Ajeigbe, H.A, B.B. Singh, J.O. Adeosun and I.E. Ezeaku, 2010. Participatory on-farm evaluation of improved legume-cereals cropping systems for croplivestock farmers: maize-double cowpea in Northern Guinea Savanna Zone of Nigeria. Afr. J. Agric. Res., 5: 2080-2088. 
Chambers, J.M., 1992. Linear Models. In: Statistical Models, Chambers, J.M. and T.J. Hastie (Eds.), Wadsworth and Brooks/Cole.

Chandrahas, A.K.G and B.H. Singh, 1989. Tobacco yield 1 forecasting models based on principal component of biometrical characters and crop inputs. I.A.S.R.I., New Delhi.

Chu, G.X, Q.R Shen and J.L. Cao, 2004. Nitrogen fixation and transfer from peanut to rice cultivated in aerobic soil in an intercropping system and its effect on soil N fertility. Plant Soil, 263: 17-27. DOI: 10.1023/B:PLSO.0000047722.49160.9e

Cochran, V.L and S.F. Schlentner, 1995. Intercropped oat and faba bean in Alaska: Dry matter production, dinitrogen fixation, nitrogen transfer and nitrogen fertilizer response. Agronomy J., 87: 420-424. DOI: 10.2134 /agronj1995.00021962008700030006x

Connolly, J., H.C. Goma and K. Rahim, 2001. The information content of indicators in intercropping research. Agric. Ecosyst. Environ., 87 : 191-207. DOI: 10.1016/S0167-8809(01)00278-X

Dago, D.N., N. Diarrassouba, K.A. Nguessan and B.M. Lamine, 2016. Computational statistics assessing the relationship between different rhizobacteria (Pseudomonas fluorescens) treatments in cereal cultivation. Am. J. Bioinform. Res., 6: 1-13. DOI: $10.5923 /$ j.bioinformatics.20160601.01

Dago, D.N, H.D.N.M. Lallié, N. Diarrassouba, S. Silué and M. Giovanni, 2015. Correlation between accuracy sensitivity specificity and positive predictive values parameters in determining differentially expressed gene. Int. J. Dev. Res., 5: 3734-3739.

Dago, D.N., D. Nafan, D.Y.S. Martial, A.M. Jean-Luc and J.F. Inza et al., 2018. Predicting maize and soybean crops dry biomass through rhizobacteria microorganism's activity on foliar bio-fertilizer in an arid agro-climate: A multiple linear regression analysis. African J. Microbiol. Res., 12: 835-848. DOI: $10.5897 / A J M R 2018.8899$

Dago, D.N., P.D. Silué, I.J. Fofana, N. Diarrassouba and H.D.N.M. Lallié et al., 2015. Development of a Statistical Model Predicting Rice Production by Rain Precipitation Intensity and Water Harvesting. I. J. Recent. Sci. Res., 6 : 6270-6276.

Dahmardeh, M., A. Ghanbari, B. Syasar and M. Ramroudi, 2009. Effect of intercropping maize with cowpea on green forage yields and quality evaluation. Asian J. Plant Sci., 8: 235-239. DOI: 10.3923/ajps.2009.235.239

Dakora, F.D., A. Spriggs, R.C. Nyemba and S.M.B. Chimphango, 2000. Hostplant Factors in the Adaptation of Indigenous African Legumes to Low pH Soils. In: Nitrogen Fixation from Molecules to Crop Productivity, Pedrosa, F.O., M. Hungria, M.G. Yates and W.E. Newton (Eds.), Dordrecht, the Netherlands: Kluwer Academic Publishers, pp: 579-580.
Dapaah, H.K., J.N. Asafu-Agyei, S.A. Ennin and C. Yamoah, 2003. Yield stability of cassava, maize, soya bean and cowpea intercrops. J. Agric. Sci., 140: 73-82. DOI: 10.1017/S0021859602002770

Davis, A.S. and M. Liebman, 2003. Cropping systems effects in giant foxtail demography: I. Green manure and tillage timing. Weed Sci., 51: 919-929. DOI: $10.1614 / \mathrm{P} 2002-133 \mathrm{~A}$

Diarrassouba, N., D.N. Dago, S. Soro, I.J. Fofana and S. Silué, 2015. Multi-Variant statistical analysis evaluating the impact of rhizobacteria (Pseudomonas fluorescens) on growth and yield parameters of two varieties of maize (Zea mays L.). Int. J. Contemporary Applied Sci., 2: 206-224.

Dhima, K.U., A.A. Lithourgidis, I.B. Vasilakoqlou and C.A. Dordas, 2007. Competition indices of common vetch and cereals intercropping in two seeding ratio. Field Crops Res., 100: 249-258. DOI: $10.1016 /$ j.fcr.2006.07.008

Dodge, Y., 2003. The Oxford Dictionary of Statistical Terms, 1st Edn., Oxford University Press, ISBN-10: 0198509944, pp: 498.

Elgersma, A., H. Schlepers and M. Nassiri, 2000. Interactions between perennial ryegrass (Lolium perenne L.) and white clover (Trifolium repens $L$.) under contrasting nitrogen availability: productivity, seasonal patterns of species composition, N2 fixation, $\mathrm{N}$ transfer and $\mathrm{N}$ recovery. Plant Soil, 221: 281-299.

Francis, O. and W.R. Stern, 1987. Cereal legume intercropping systems. Advance Agronomy, 41: 41-90. DOI: $10.1016 / \mathrm{S} 0065-2113(08) 60802-0$

Franklin, S.B., D.J. Gibson, P.A. Robertson, J.T. Pohlmann and J.S. Fralish, 1995. Parallel analysis: A method for determining significant principal components. J. Vegetation Sci., 6: 99-106. DOI: $10.2307 / 3236261$

Gabriel, K.R. and C.L. Odoroff, 1990. Biplots in biomedical research. Stat. Med., 9: 469-485. DOI: $10.1002 / \mathrm{sim} .4780090502$

Giller, K.E. and G. Cadisch, 1995. Future benefits from biological nitrogen fixation: an ecological approach to agriculture. Plant Soil, 174: 255-277. DOI: 10.1007/978-94-011-0053-3_13

Halimah, B.Z., R. Peter, P. Maria, O. Patrick and S. Heiko, 2009. Visual Informatics.

Halli, S.S. and K.V. Rao, 1992. Advanced techniques of population analysis.

Izaurralde, R.C., N.G. Juma and W.B. McGill, 1990. Crop and nitrogen yield of barley and barley-field pea intercrop in cryoboreal-subhumid central Alberta. Agron. J., 82: 295-301. DOI: 10.2134 /agronj1990.00021962008200020024x 
Jain, R.C., H. Sridharan, R. Agrawal, 1984. Principal component technique for forecasting of sorghum yield. Indian J. Agric. Sci., 54: 467-470.

Jain, R.C. and R. Agrawal, 1992. Probability model for crop yield forecasting. Biometrical J., 27: 435-439. DOI: $10.1002 /$ bimj.4710340410

John, R.H., 2009. Numerical methods for nonlinear engineering models.

Konlan, S., J. Sarkodie-Addo, M.J. Kombiok, E. Asare and I. Bawah, 2013. Yield response of three groundnut (Arachis hypogaea L.) varieties intercropped with maize (Zea mays) in the guinea savanna zone of Ghana. J. Cereals Oilseeds, 6: 7684. DOI: $10.5897 /$ JCO2013.0112

Li, L., F.S. Zhang, X.L. Li, P. Christie and J.H. Sun, et al., 2003. Interspecific facilitation of nutrient uptake by intercropped maize and faba bean. Nutrient Cycling Agroecosystems, 68: 61-71. DOI: $10.1023 / \mathrm{A}: 1021885032241$

Michael, K., C.F. Angelinus, A.N. Samuel, D.K.A. Benjam and C.A. Robert et al., 2017. Maize-grain legume intercropping for enhanced resource use efficiency and crop productivity in the Guinea savanna of northern Ghana. Field Crops Res., 213: 38-50. DOI: 10.1016/j.fcr.2017.07.008S

Morris, R.A. and D.P. Garrity, 1993. Resource capture and utilization in intercropping: Non-nitrogen nutrients. Field Crops Res., 34: 319-334. DOI: $10.1016 / 0378-4290(93) 90120-\mathrm{C}$

Mpairwe, D.R., E.N. Sabiiti, N.N. Ummuna, A. Tegegne and P. Osuji, 2002. Effect of intercropping cereal crops with forage legumes and source of nutrients on cereal grain yield and fodder dry matter yields. Afr. Crop Sci. J., 10: 81-97. DOI: 10.4314/acsj.v10i1.27559

Ndlovu, P., K. Mazvimavi, H. An and C. Murendo, 2014. Productivity and efficiency analysis of maize under conservation agriculture in Zimbabwe. Agric. Syst., 124: 21-31. DOI: 10.1016/j.agsy.2013.10.004

Nin-Pratt, A. and L. McBride, 2014. Agricultural intensification in Ghana: Evaluating the optimist's case for a Green Revolution. Food Policy, 48: 153-167. DOI: 10.1016/j.foodpol.2014.05.004

Noel, D.D., J.F. Inza, D. Nafan, L.B. Mohamed and A.M. Jean-Luc et al., 2019. A quick computational statistical pipeline developed in $r$ programing environment for agronomic metric data analysis. Am. J. Bioinform. Res., 9: 22-44. DOI: 10.5923/j.bioinformatics.20190901.03.

Noel, D.D., D. Nafan, S. Souleymane, M.A. Jean-Luc and F. Jesus et al., 2016. Combination of rizhobacteria and foliar bio-fertilizer accelerating maize and soybean crop plants growth process in arid soil. Acad. J. Agric. Res., 4: 446-456.
Ofuso-Amin, J. and N.V. Limbani, 2007. Effect of intercropping on the growth and yield of cucumber and okra. Int. J. Agric. Biol., 9: 594-597.

Olufemi, O., R. Pitan and J.A. Odebiyi, 2001. The effect of intercropping with maize on the level of infestation and damage by pod-sucking bugs in cowpea. Crop Protect., 20: 367-372. DOI: 10.1016/S0261-2194(00)00135-6

Patrick, A.N., 2006. Manipulating legume/cereal mixtures to optimize the above and below ground interactions in the traditional African cropping systems. African J. Biotechnol., 5: 2526-2533.

Peoples, M.B., K.E. Giller, D.F. Herridge and J.K. Vessey, 2002. Limitations to Biological Nitrogen Fixation as a Renewable Source for Nitrogen for Agriculture. In: Nitrogen Fixation: Global Perspective, Finan, T.O., M. Brian, D. Layzell, K. Vessey and W. Newton (Eds.), CAB International, UK, pp: 356-360.

Rusinamhodzi, L., M. Corbeels, J. Nyamangara and K.E. Giller, 2012. Maize-grain legume intercropping as an attractive option for ecological intensification that reduces climatic risk for smallholder farmers in central Mozambique. Field Crop Res., 136: 12-22. DOI: $10.1016 /$ j.fcr.2012.07.014

Core Team, R., 2018. R: A language and environment for statistical computing. R Foundation Statistical Comput., Vienna.

Sandra, L.A., 1994. PHB practical handbook of curve fitting. CRC Press.

Saucke, H. and K. Ackermann, 2006. Weed suppression in mixed cropped grain peas and false flax (Camelina sativa). Weed Res., 46: 453-461. DOI: $10.1111 / \mathrm{j} .1365-3180.2006 .00530 . \mathrm{x}$

Shaharoona, A.A.Z., A.B. Muhammad and A. AzeemKalid, 2006. Performance of Pseudomonas spp. containing ACC deaminase for improving growth and yield of maize (Zea mays L.) in the presence of nitrogenous fertilizer. Soil Biol. Biochem. 38: 2971-2975. DOI: 10.1016/j.soilbio.2006.03.024

Stern, W.R., 1993. Nitrogen fixation and transfer in intercrop systems. Field Crops Res., 34: 335-356. DOI: 10.1016/0378-4290(93)90121-3

Szumigalski, A. and A.R. Van, 2005. Weed suppression and crop production in annual intercrops. Weed Sci., 53: 813-825. DOI: 10.1614/WS-05-014R.1

Takim, F.O., 2012. Advantages of maize-cowpea intercropping over sole cropping through competition indices. J. Agric. Biodiversity Res., 1: 53-59.

Umesha, S., M. Divya, K.S. Prasanna, R.N. Lakshmipathi and K.R. Sreeramulu, 2014. Comparative effect of organic and bio-fertilizer on growth and yield of maize (Zea mays. L). Current Agric. Res. J., 2: 55-62. DOI: 10.12944/CARJ.2.1.08

Willey, R.W., 1990. Resource uses in intercropping systems. Agric. Water Manage., 17: 215-231. DOI: 10.1016/0378-3774(90)90069-B 
William, M.K., 1984. Curve fitting for programmable calculators. Syntec, Incorporated.

Yilmaz, S., M. Atak and M. Erayman, 2007. Identification of advantages of maize-legume intercropping over solitary cropping through competition indices in the East Mediterranean Region. Turkey J. Agric., 16: 217-228.

Zhang, F.S. and L. Li, 2003. Using competitive and facilitative interactions in intercropping systems enhances crop productivity and nutrient-use efficiency. Plant Soil, 248: 305-312.

DOI: $10.1007 / 978-94-010-0243-126$
Zwick, W.R. and W.F. Velicer, 1986. Comparison of five rules for determining the number of components to retain. Psychol. Bulletin, 99: 432-442.

DOI: 10.1037//0033-2909.99.3.432 